Jan Philipp Schaefer

\title{
Die Umgestaltung des Verwaltungsrechts
}

Kontroversen reformorientierter Verwaltungsrechtswissenschaft

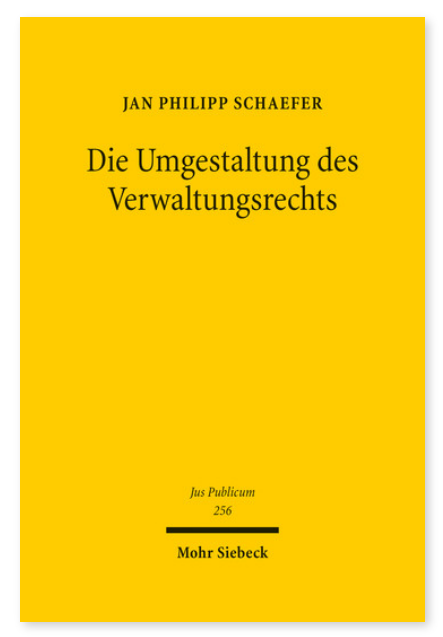

2016. XIV, 514 Seiten. JusPubl 256

ISBN 978-3-16-154109-4

DOI 10.1628/978-3-16-154109-4

eBook PDF 119,00€

ISBN 978-3-16-154068-4

Leinen $119,00 €$
Die Häutungen des Leviathan vom bürokratisch-bewirkenden zum gewährleistend-aktivierenden Staat rufen eine »Neue Verwaltungsrechtswissenschaft « auf den Plan. In der Auseinandersetzung mit der Europäisierung der Rechtsordnung, der Privatisierung öffentlicher Ressourcen und dem Formwandel des politisch-administrativen Systems stellt sie Prämissen des Verwaltungsrechts und somit die analytische Differenzierung von Staat und Gesellschaft sowie von Staat und Union in Frage. Anhand konsensual operierender Staatlichkeit und privater Rechtsetzung, Auffangverbünden zwischen Zivilrecht und öffentlichem Recht, Privatisierungs- und Regulierungsverwaltungsrecht werden Innovationspotentiale reformorientierter Verwaltungsrechtswissenschaft ausgeleuchtet, werden hermeneutische und kulturwissenschaftliche Varianten der Jurisprudenz gegeneinandergestellt. Ausgehend von Max Webers paradigmatischer Beschreibung des hierarchischen Verwaltungsstaates werden Trennungs- und Verbindungslinien zu moderneren Beschreibungskontexten - Steuerungs- und Governance-Theorie, Systemtheorie, ökonomische Analyse des Rechts - aufgezeigt.

Jan Philipp Schaefer ist wissenschaftlicher Mitarbeiter am Lehrstuhl für Öffentliches Recht, Verfassungstheorie und Rechtsphilosophie der Universität Heidelberg.
Jetzt bestellen:

https://mohrsiebeck.com/buch/die-umgestaltung-des-verwaltungsrechts-9783161541094?no_cache=1 order@mohrsiebeck.com

Telefon: $+49(0) 7071-923-17$

Telefax: $+49(0) 7071-51104$ 